\title{
Pathological analysis of cystic lesions of the bones: retrospective single-center 10 -year overview
}

\author{
Gonca Özgün${ }^{1}$, Ulviye Yalçınkaya², Zeynep Yazıcı ${ }^{3}$, Bartu Sarısözen ${ }^{4}$ \\ ${ }^{1}$ Department of Pathology, Başkent University School of Medicine, Ankara, Turkey \\ ${ }^{2}$ Department of Pathology, Uludağ University School of Medicine, Bursa, Turkey \\ ${ }^{3}$ Department of Radiology, Uludağ University School of Medicine, Bursa, Turkey \\ ${ }^{4}$ Department of Orthopaedics and Traumatology, Uludağ University School of Medicine, Bursa, Turkey
}

DOI: $10.18621 /$ eurj.345991

\begin{abstract}
Objective: Many different neoplastic and non-neoplastic lesions involve the skeletal system. Clinical and radiological tools primarily assess the nature of these lesions. The aim of this study was to analyze the cystic bone lesions in a pathologic point of view.

Methods: All bone cysts between 2002 and 2013 retrospectively evaluated under the guidance of clinical information and radiological images. Descriptive data such as age, gender, tumor site, symptoms, and clinical and radiological findings obtained from the hospital's database system.

Results: There were 96 cystic bone lesions; 47 were aneurysmal bone cysts (ABCs), 37 were simple bone cysts (SBCs), one was a lesion with features of both $\mathrm{ABC}$ and $\mathrm{SBC}$, four were intraosseous ganglia, four were epidermoid cysts, and three were hydatid cysts. The mean ages of the patients with ABCs and SBCs were 18.7 \pm 12.8 years (range, 3-75 years) and 23.8 \pm 13.3 years (range, 3-62 years), respectively. Most of the lesions located in the long bones.

Conclusions: Cystic lesions of the bone rarely encountered in daily pathology routine. As with all conditions affecting the skeletal system, one of the most important steps towards an accurate pathological diagnosis is to perform with clinical and radiological information while evaluating the patients.
\end{abstract}

Keywords: Aneurysmal bone cyst, simple bone cyst, intraosseous ganglion, hydatid cyst, epidermoid cyst

Received: October 23, 2017; Accepted: January 25, 2018; Published Online: March 1, 2018

A neurysmal bone cyst (ABC), simple bone cyst (SBC), and their combinations, usually considered non-neoplastic cystic lesions. Other cystic lesions that may encounter in bone tissue include intraosseous ganglion cysts of undetermined origin, epidermoid cysts, and hydatid cysts of infectious origin [1]. Bone cysts may develop as solitary or multiple lesions. Cystic bone lesions may mimic and behave similarly to a bone tumor [2].

The aim of this study was to analyze the cystic bone lesions in a pathologic point of view.

\section{METHODS}

All bone cysts diagnosed between 2002 and 2013 were retrospectively evaluatedfrom the archives. The samples sent to the pathology department various surgical methods: bone curettage, excision, and biopsy. Macroscopically, the samples were hemorrhagic, irregular tissues containing areas having the hardness of bone as well. All material routinely fixed in $10 \%$ buffered formalin and embedded in paraffin. The pathological evaluation based on routine

Address for correspondence: Gonca Özgün, MD., Assistant Professor, Başkent University School of Medicine, Department of Pathology, 79. Cadde, No:7/4, Bahçelievler, 06490 Ankara, Turkey

E-mail: gbarit@gmail.com,Phone:+90 312 2126591,Fax:+90 3122127572 
hematoxylin-eosin stained slidesunder the guidance of clinical information and radiological images. The age of the patients, gender, localization, symptoms, and clinical and radiological findings obtainedfrom the hospital's database system. The collected information has transferred to the preformed forms to do the statistical analysis. The institutional Ethical committee guidelines conducted the study.

\section{Statistical Analysis}

The statistical analysiswas performed with SPSS statistical software for Windows, version 20.0 (SPSS Inc, Chicago, IL, USA). Descriptive analysis such as frequency, percentage, mean \pm standard deviation, and range (min-max)was used for the patient groups.

\section{RESULTS}

Of the 96 cystic bone lesions in the overview, 47 were $\mathrm{ABCs}, 37$ were SBCs, one was a cystic lesion with features of both aneurysmal and simple bone cyst, four were intraosseous ganglia, four were epidermoid cysts, and three were hydatid cysts.

The mean age of the patients with ABCs was 18.7 \pm 12.8 (range, 3-75 years). Of these 47 patients, 23 were female, and 24 were male. The lesions located in the lower extremities in 27 patients, the upper extremities in 6 patients, the sacrum in 5 patients, the vertebrae in 3 patients, the skull in 3 patients, the ribs in 2 patients, and the clavicula in 1 patient. There were concurrent lesions with the ABCs in 6 patients (Table

Table 1. Characteristics of the aneurysmal bone cysts.

\begin{tabular}{lc}
\hline Characteristics & Data (n= 47) \\
\hline Age at diagnosis (years) & $18.7 \pm($ range, 3-75 years) \\
Male/Female & $24 / 23$ \\
Localization & 27 \\
Lower extremities & $(12 / 9 / 3 / 3)$ \\
(Femur/tibia/fibula/bones of the feet) & 5 \\
Pelvis & 3 \\
Vertebra & 6 \\
Upper extremities & $(2 / 2 / 2)$ \\
(Humerus/radius/bones of the hands) & 6 \\
Others & \\
Concurrent lesions & 2 \\
Giant cell tumor & 1 \\
Intraosseous lipoma & 1 \\
Ossifying fibroma & 1 \\
Fibrous dysplasia & 1 \\
Reparative granuloma & 5 \\
Recurrence & \\
\hline
\end{tabular}

Table 2. Characteristics of the simple bone cysts.

\begin{tabular}{lc}
\hline Characteristics & Data $(\mathbf{n}=\mathbf{3 7})$ \\
\hline Age at diagnosis (years) & $23.8 \pm 13.3$ (range, 6-62 years) \\
Male/Female & $23 / 14$ \\
Localization $\quad$ \\
$\quad$ Humerus & 13 \\
$\quad$ Femur & 9 \\
$\quad$ Tibia & 4 \\
$\quad$ Pelvis & 3 \\
$\quad$ Bones of the feet and hands) & 5 \\
$\quad$ Others & 3 \\
Concurrent lesions & \\
$\quad$ Fallus & 1 \\
Recurrence & 3 \\
\hline
\end{tabular}




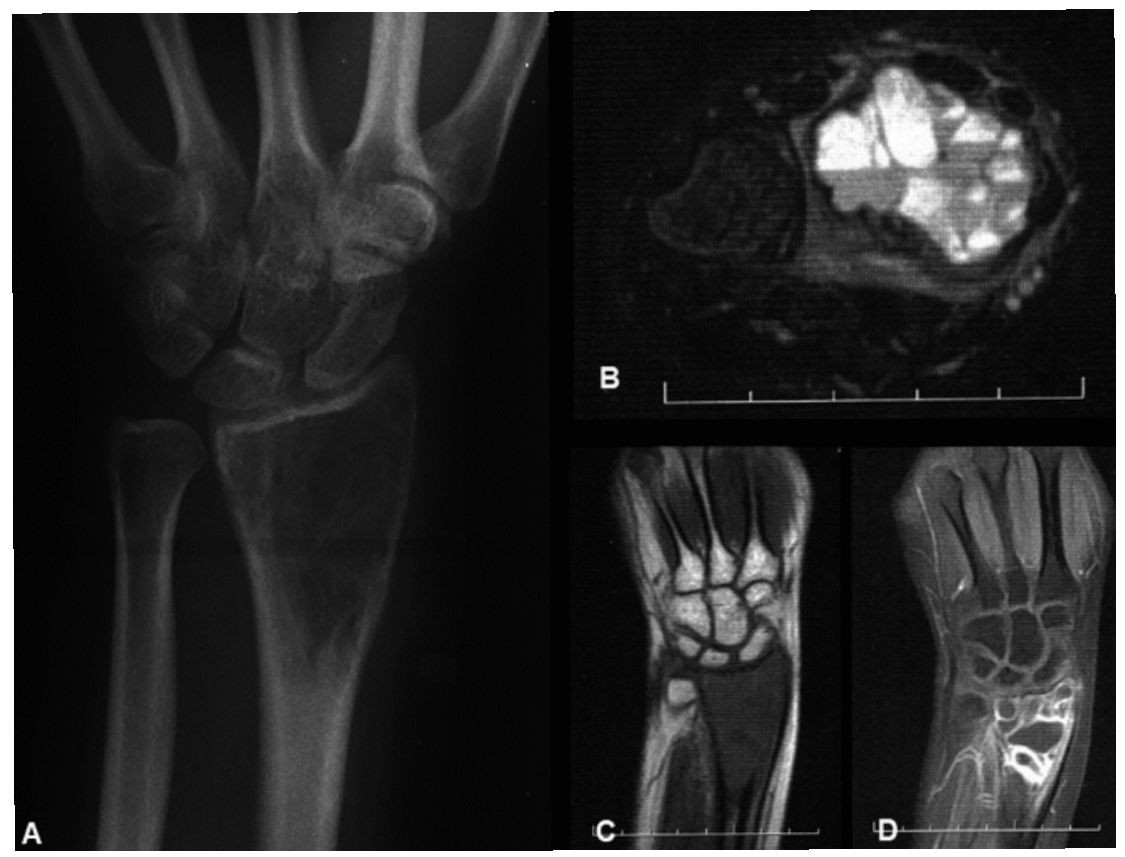

Figure 1. Aneurysmal bone cyst of a 20-year-old woman. A. The anteroposterior radiographshowed an osteolytic, moderately expansile lesion in the distal radial metaphysis. B. Axial T2-weighted MR image showed multiple fluid-fluid levels within the lesion. C. Coronal T1-weighted MR image of the lesion. D. On contrast-enhanced coronal T1-weighted MR image,there was an enhancement of the cyst wall and internal septations.

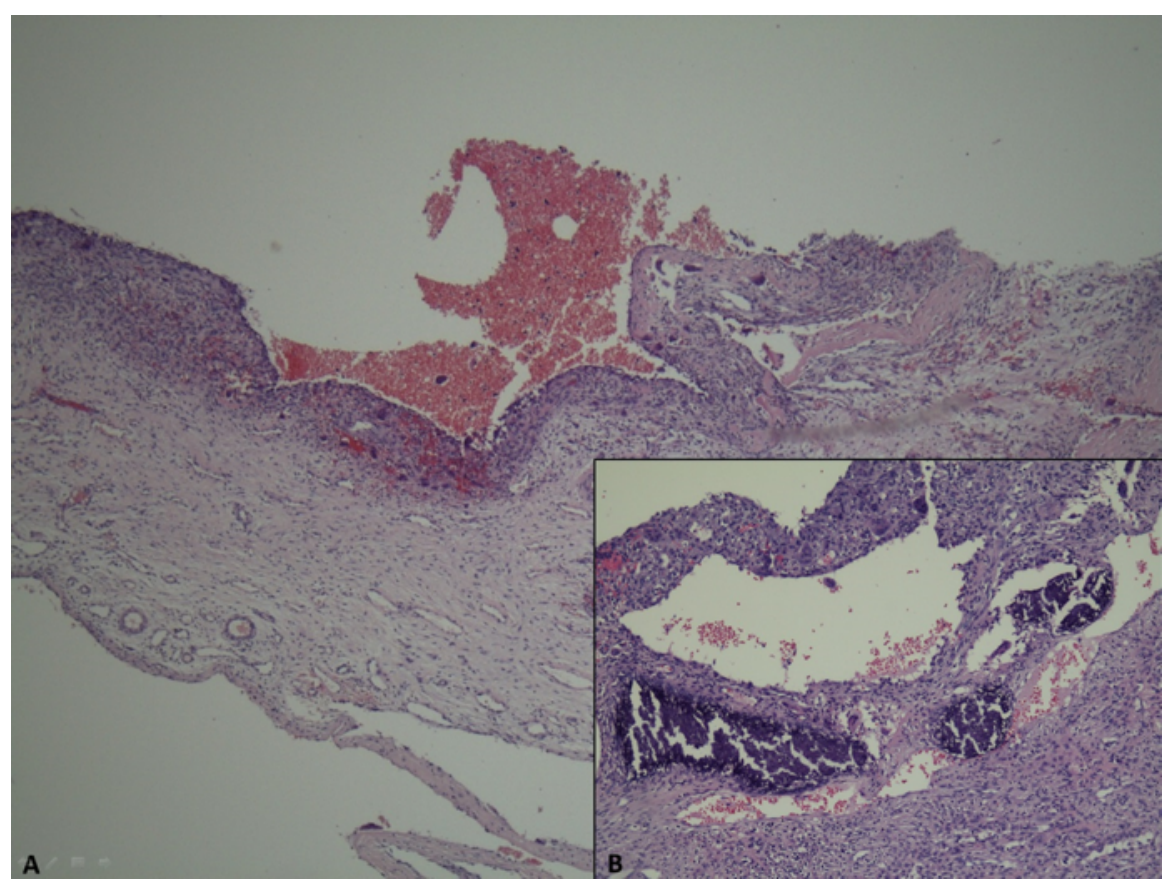

Figure 2. Aneurysmal bone cyst. A. Fibrous cyst wall and a blood-filled cavernous spacewithout endothelial lining were seen. The fibrous wall contained multiple multinuclear giant cells andspindle fibroblasts (Hematoxylin-eosin $\times 40$ ). B. Patchy areas of the basophilic bone formationcalled "blue bone" were noted (Hematoxylin-eosin $\times 100)$. 


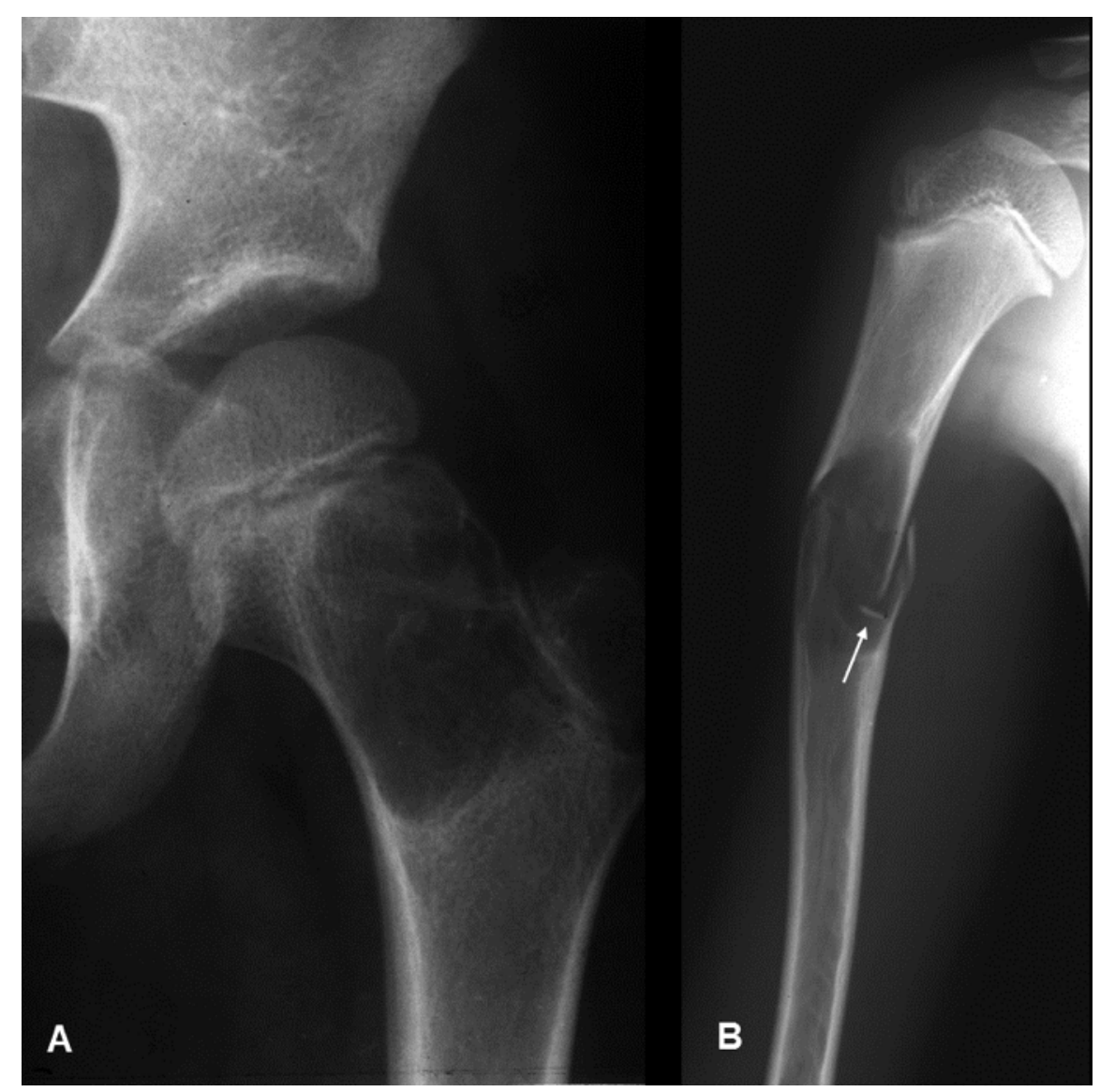

Figure 3. Simple bone cyst. A. A child with a simple bone cyst in the femoral neck. The anteroposterior radiograph showed a welldefined medullary lytic lesion with moderatecortical thinning. B. A child patient with a simple bone cyst in the humerus. The anteroposteriorradiograph revealed the cyst complicated by a pathologic fracture. A fragment of the cortex(arrow) was lying medially within the cyst (fallen fragment sign).

1). In 2 patients the cystic bone lesions reported as solid ABC. There were five patients with a recurrence, however, none of them underwent malignant transformation in the clinical follow-up time. Microscopic examination revealed blood-filled cavernous spaces without an endothelial lining surrounded by a fibrous wall. The fibrous wall contained multiple multinuclear giant cells, spindle fibroblasts with mitotic figures, and patchy areas of new bone production (Figure 1). No cytologic atypia or atypical mitotic figures observed.

The majority of cases with an SBC were male (23 males, 14 females). The mean age of these patients was $23.8 \pm 13.3$ years (range, $3-62$ years). The lesions located in the lower extremities in 18 patients, the upper extremity in 16 patients, and the pelvis in 3 patients (Table 2). SBCs co-occurred with another lesion in four of these patients. The lesions recurred after excision in 2 patients. There was not any malignant transformation. Microscopically, a thin fibrous cystic wall with interspersed benign giant cells was observed. Patchy areas of hemosiderin-laden macrophages and cell aggregates consisting of mononuclear inflammatory cells were also noted (Figure 2). In cases with accompanying fracture healing and callus formation, proliferating fibroblasts and callus formation were present on the cyst wall and inside the cyst lumen. The patient in whom had a mixed cystic lesion consisting of an $\mathrm{ABC}$, and an $\mathrm{SBC}$ was a 12-year-old boy. The lesion located in the distal part of the right tibia.

Comparing the two most common cystic bone lesions, $\mathrm{ABCs}$ and $\mathrm{SBCs}$, the male-female distribution was equal in the cases with $\mathrm{ABCs}$, whereas in SBCs there was a male predominance. The mean age of the patients with SBCs was higher than those with ABCs. The recurrence rate was higher in $\mathrm{ABCs}$ than for SBCs. 


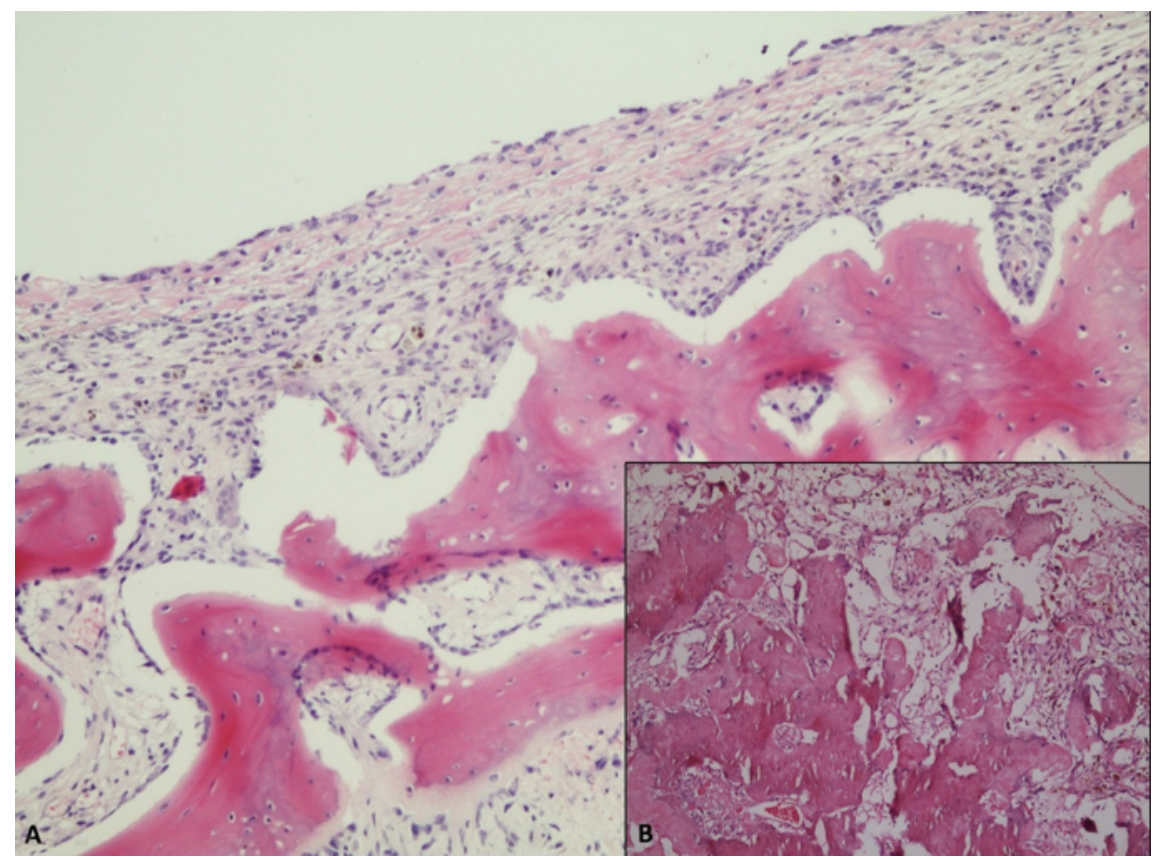

Figure 4. Simple bone cyst. A. cyst wall composed of collagen and thin fibrous tissue, which contained giant cells and hemosiderinladen macrophages (Hematoxylin-eosin $\times 100$ ). B. The cystwall contained abundant and irregular fibrin deposits (Hematoxylin-eosin $\times 100$ )

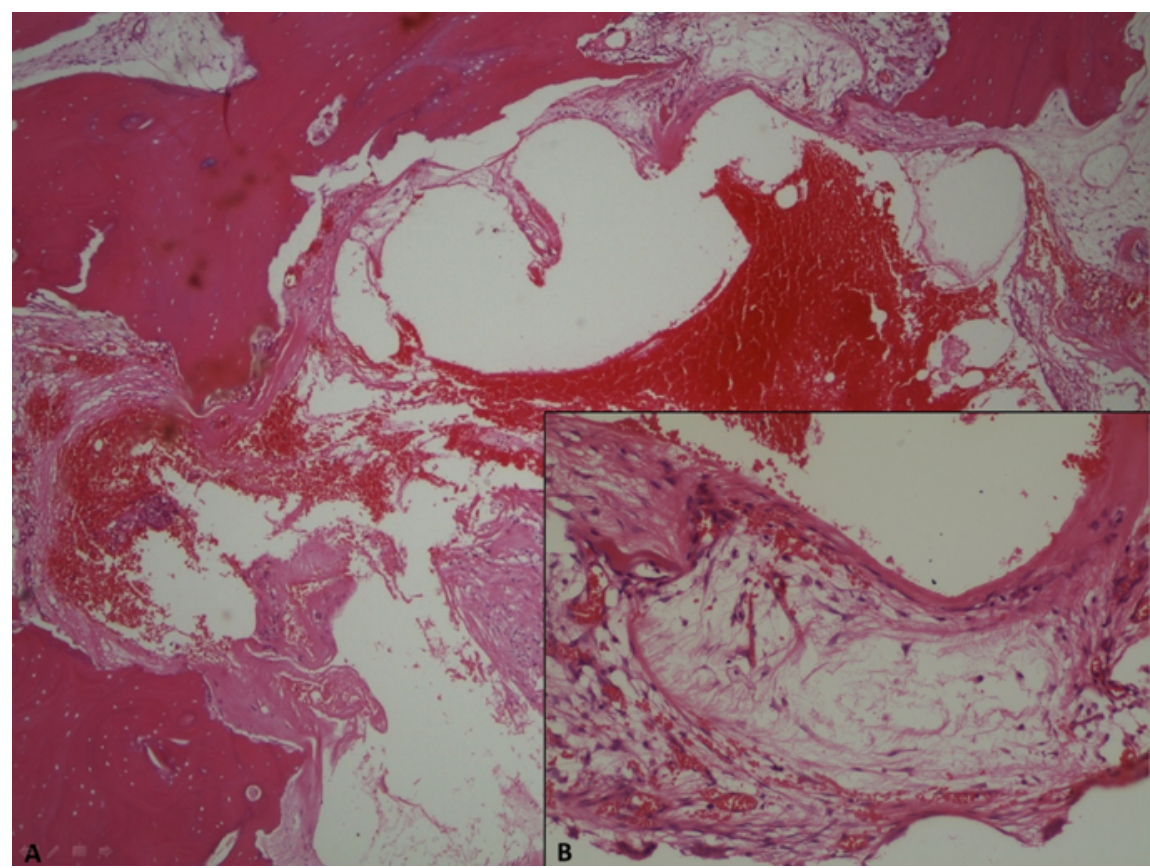

Figure 5. Intraosseous ganglion cyst. A. Thin fibrous cyst walls without an endothelial liningbetween the bony trabeculas were seen (Hematoxylin-eosin $\times 40)$. B. Myxoid changes werepresent in the cyst wall $($ Hematoxylin-eosin $\times 200)$ 


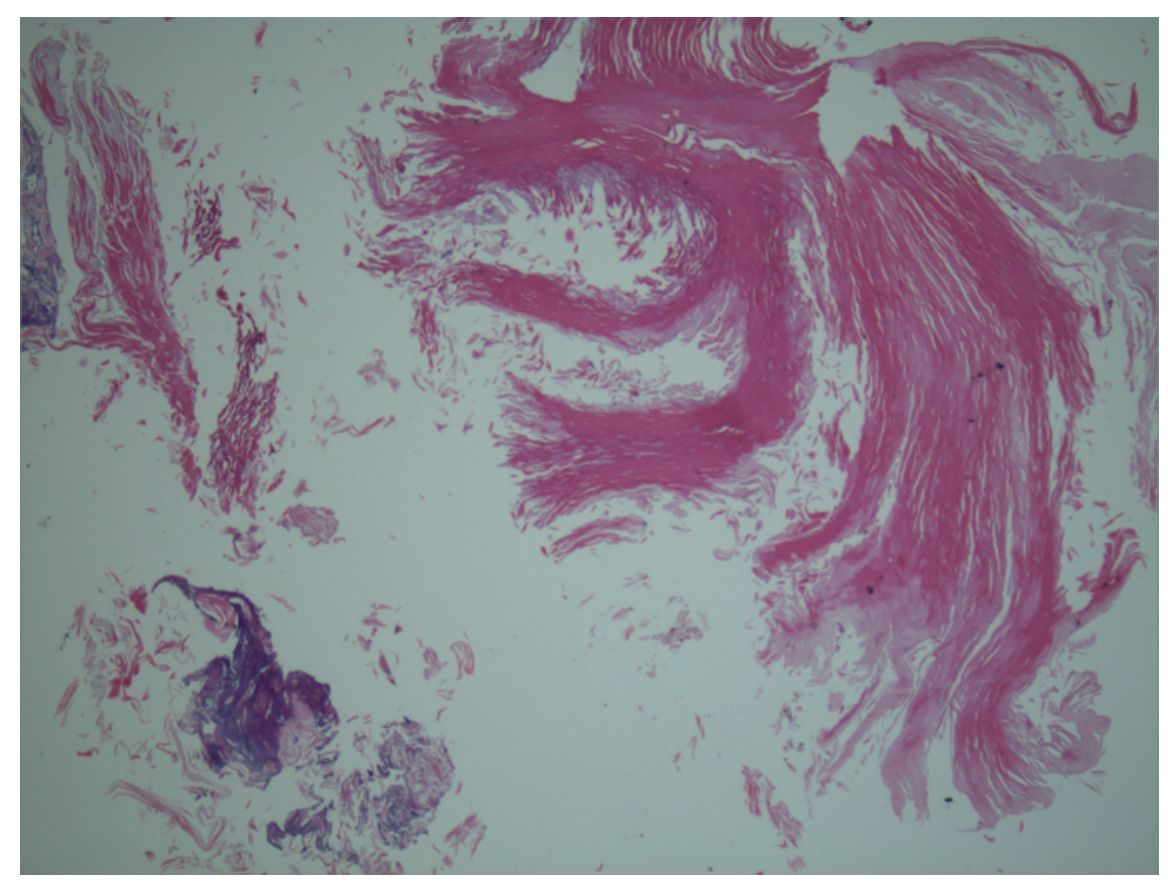

Figure 6. Epidermoid cyst. Keratinous material intermingled with the bone fragments (Hematoxylin-eosin $\times 40)$

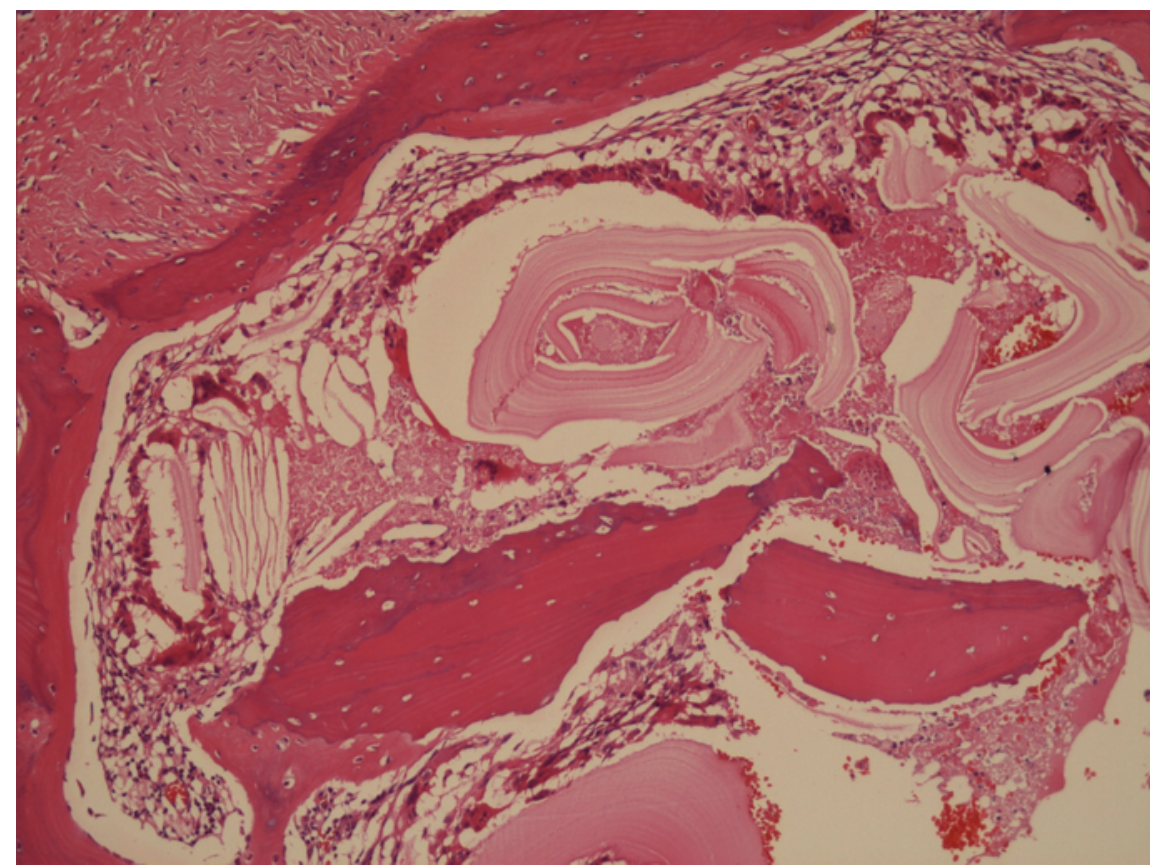

Figure 7. Hydatid cyst. Germinative membranous structures are seen between the fibrouscyst wall and the bone fragments (Hematoxylin-eosin $\times 100$ ) 
Intraosseous ganglion cysts and epidermoid cysts were also present in our 10-year bone cyst archive. There were four intraosseous ganglion cyst patients. The mean age of the patients was $42 \pm 12.1$ years (range, 30-58 years). Three of them were female, and one of them was male. The lesions located in the acetabulum in three of these patients and the foot lateral in one patient. Microscopic examination demonstrated a thin fibrous cyst wall with mucinous content. Myxoid changes were present on the cyst wall between areas of loose fibroblastic proliferation (Figure 3). Three of the patients with epidermoid cysts were female, and one was male. Their mean age was $17.7 \pm 12.4$ years (range, $1-31$ years). The location was distal phalanx in three patients and the orbital bone in one patient. The microscopic evaluation showed cystic spaces lined with keratinized squamous epithelium (Figure 4). Our case series included three intraosseous hydatid cysts located in the femur in two patients and the vertebrae in one patient. Two of these patients were male, and one was female; their mean age was $44.6 \pm$ 21.7 years (range, 25-68 years). Microscopically, these lesions characterized by a fibrous cyst wall, a germinative membranous structure on the internal surface, and a few scolices (Figure 5).

\section{DISCUSSION}

\section{Aneurysmal bone cysts}

$\mathrm{ABCs}$ are not considered neoplastic lesions because they may show signs of regression, even after incomplete resection [3]. However, cytogenetic and molecular studies showing karyotypic anomalies on the short arm of chromosome 17 have suggested that the primary $\mathrm{ABCs}$ are neoplastic lesions rather than reactive lesions [4-6]. This cyst may be encountered in all age groups although they have been most commonly reported during the first two decades of life, with a slightly higher prevalence in women compared to men [7]. Pain and swelling are the main symptoms, although compressive symptoms are also sometimes present when the lesions are located in the vertebrae [1]. Our case series also showed that 34 $(72.3 \%)$ patients were in their first two decades. The female-to-male ratio was $0.95(23 / 24)$. Our case series also revealed that pain and swelling were the most prevalent symptoms.
$\mathrm{ABCs}$, which are composed of blood-filled spaces separated by fibroblasts, osteoclast-type giant cells, and septae consisting of reactive woven bone, may develop either de novo or secondary to hemorrhagic cystic changes due to benign or malignant bone tumors [1]. They may grow in all types of bone although they tend to be located in the metaphysis of long bones, mainly the femur, tibia, and humerus, as well as the posterior portions of the vertebral bodies; $70-80 \%$ of all aneurysmal bone cysts are found in these two localizations [7]. In our case series, 29 $(61.7 \%)$ of the aneurysmal bone cysts were found in the long bones and the vertebrae (Table 1).

Radiological images vary depending on the stage of the lesion and its relationship with the adjacent bone. Eccentric localization is common in long tubular bones, whereas central and parosteal lesions are less common [7, 8]. In earlier stages, lesions appear as small, typically eccentric, and infiltrative masses that do not widen the bone. During the growth phase, they are characterized by marked cortical lysis and destruction. In their stable phase, they may have the classic appearance of an ABC marked by a widened lesion with multiple internal trabeculations and an osseous periphery, which distorts the pattern of host bone. In the healing phase, on the other hand, they appear as irregular, coarsely trabecular, osseous lesions as a result of progressive ossification of the lesion [9].

ABCs may be primary, or they may co-occur with or develop secondary to another lesion. Most ABCs are labeled primary, although development secondary to a preexisting lesion that described in $20-30 \%$ of cases [10]. Many secondary ABCs reported in the literature [11-14]. It indicated that ABCs accompany, in descending order, giant cell tumors of the bone, chondroblastoma, chondromyxoid fibroma, and fibrous dysplasia [6]. In our case series, six patients had accompanying lesions to ABCs: two of them secondary to giant cell tumors, one of them to ossifying fibroma, one of them to fibrous dysplasia, one of them to intraosseous lipoma, and one of them to giant cell reparative granuloma.

Microscopically, ABCs consist of multiple bloodfilled cavernous spaces without a muscular layer or an endothelial lining. There are also fibrous walls that separate these areas. Fibroblasts, histiocytes, giant cells, inflammatory cell infiltration, osteoid, and 
chondroid can be found on the fibrous walls [5]. The osteoid usually has a trabecular pattern. It is entirely composed of fibrous septa-like cellular components and contains no or focally distributed widened vascular spaces in its solid variant [15]. It has been reported that solid variant of $\mathrm{ABC}$ s usually located in the posterior segments of the vertebral bones $[16,17]$. However, two patients in our series (age; 20 and 22 years) had femoral and calcaneal locations.

Differential diagnosis must include giant cell tumors of the bone, low-grade osteosarcoma, and telangiectatic osteosarcoma. The fibrous septa of ABCs also contain multiple giant cells; however, the age of the patient and the metaphyseal location of the lesion are helpful hints in the differential diagnosis. Low-grade osteosarcomas contain fewer mitoses and low cellularity compared to a typical ABC [3].

Many mitotic figures may be observed, especially in the osteoid-containing areas, which creates a challenge in the differential diagnosis from telangiectatic osteosarcoma [5]. Radiologically, a smooth border, an irregular appearance, and a thin calcific line in the cortical bone indicate aneurysmal bone cysts. Microscopically, the absence of anaplastic cells and atypical mitotic figures in the fibrous trabeculae, as well as an osteoid pattern that is parallel and linear to the septae, favor the diagnosis $[18,19]$. In approximately $1 / 3$ of the cases, a basophilic bone formation called "blue bone" may be noted, albeit non-diagnostic [1].

The prognosis of aneurysmal bone cysts is quite favorable. There are case reports in the literature suggesting malignant transformation although this is not an expected finding in general [3, 20-22]. We detected recurrence in five $(10 \%)$ cases with age range of 8 to 25 years. Recurrent lesions located in the lower extremity and the pelvis in four patients and the maxilla in one patient. In one patient, there was a solid component seen microscopically, which recurred later. None of the cases in our series had a malignant transformation.

\section{Simple bone cysts}

SBCs of undetermined origin are considered reactive or developmental lesions. They constitute roughly $3 \%$ of cases biopsied from bone tissue. These lesions create an irregularity in the epiphysis plaque. They are usually observed in the second decade with a prevalence three times higher in men [3]. In our case series, $20(54 \%)$ patients were in their 2 nd decade. The number of males and females were 23 and 14 , respectively, with a ratio of 1.6. The majority of these lesions is found in the humerus, femur, and tibia [1, 6]. We similarly found that $26(70.2 \%)$ of the SBCs in our case series located in the humerus, femur, and tibia (Table 2). Patients may present with pain. The SBCs could locate adjacent to a pathological fracture or present as an incidental radiological finding [8]. Likewise, four cases in our case series presented with pathological fractures, whereas the other patients were admitted with pain and swelling.

SBCs appear as lesions that may be trabeculated or multiloculated and appear as cystic masses located at the metaphysis in relation with the epiphysis plaque. Cortical thinning, erosion and widening may be present; however, the cortical bone is not destroyed. The growth rate of cystic lesions that are about the epiphysis plaque is slower than that of bone. Therefore, they may appear as metaphyseal cystic lesions in patients of advanced age [7, 23].

Histologically, there is a cyst wall composed of collagen and thin fibrous tissue, which contains giant cells, hemosiderin-laden macrophages, and lymphocytes. The cyst wall may contain abundant, irregular, and sometimes calcific fibrin deposits [7]. Because SBCs may have a giant cell component, the differential diagnosis must include giant cell tumors of the bone. The presence of septae in the lesion should raise the suspicion of an ABC [24]. In SBCs, the presence of a fracture is an indication for surgery. Spontaneous regression takes place in $15 \%$ of cases; however, the majority of these lesions do not regress, and they even progress.

\section{Ganglion cysts}

An intraosseous ganglion resembles a 'ganglion' that is located in a tendon sheath, and it is composed of spaces filled with mucoid fluid. Patients are asymptomatic, and these cysts are incidentally detected in radiological studies. Patients may present with pain in the presence of a fracture [3]. In a study of 88 patients, the intraosseous ganglion was most commonly located in the hip and adjacent structures [25]. In our case series, three cases were found in the acetabulum and one in the ankle. Cases with metacarpal and vertebral locations have also reported 
$[26,27]$. These cysts have usually been reported in young and middle-aged adults [27]; the age range in our study was between 30 and 58 years (mean: 42 years). Three of these patients were female, and one was male. In our series, the presenting symptom of all the patients was a pain.

Radiologically, these cysts are lytic masses with well-defined borders which widen the joint cartilage. A sclerotic margin is evident at the periphery of the lesion [28]. Histopathological examination shows a fibrous cyst wall and mucinous material within the cyst. Differential diagnosis must include degenerative joint disease. The absence of any degenerative lesion in the adjacent joint may suggest the diagnosis $[3,29]$.

\section{Epidermoid cysts}

Epidermoid cysts with intraosseous location are rare non-neoplastic lesions in the jaw bone, distal phalanges, or the skull [30]. They are frequently located in the skull and distal phalanges. Location in the skull is thought to occur as a result of developmental defects, whereas distal phalangeal locations are considered secondary to traumatic implantations of squamous epithelium. The most common complaint is swelling of the bone [7]. These cysts have a low growth rate, leading to a marked widening in the host bone. They may also extend to the soft tissues nearby, altering the clinical picture. Cases in which the lesion is located in the skull and extends intracranially may present with a clinical picture resembling that of a brain tumor [31]. Three patients in our case series had a distal phalangeal location, and one had a maxillary location with extension to the orbital soft tissue. Case series in literature have reported an age range of 21 to 69 years, with the majority of cases being male (87.5\%) [30]. In our series, three female and one male case were present with an age range of 1 to 31 years (mean: 17.7 years). They presented with pain and swelling.

Radiologic studies have shown that these lesions have a considerably well-defined border with a sclerotic ring. The cortical bone is usually thinned and widened. Histopathological diagnosis is made by noting the cyst wall lined by a squamous epithelium that produces keratin, even if in a focal area [3, 32].

\section{Hydatid cysts}

Echinococcosis is a common parasitic infection in countries where livestock farming is practiced. It tends to be localized, in particular, in the liver, lung, and brain. Approximately $3 \%$ of all hydatidosis cases are localized in bone, with a predilection for vertebral bones, long bones, and pelvic bones [33]. Patients may present with symptoms of spinal compression when lesions are localized to the vertebral column [34-36]. Two of our cases located in the femur, while one located in vertebra. One of the cases in the femur extended to the soft tissue of the thigh. The pain was the primary symptom in both the femoral and vertebral lesions. Two of our patients were male, and one was female; their ages ranged between 25 and 68 years (mean: 44.6 years). Radiologically, the pathognomonic appearance of these lesions is the presence of sister vesicles in the cyst lumen [36].

\section{CONCLUSION}

Cystic lesions of the bone are not frequently encountered. Differential diagnoses must also include malignant bone tumors. As in all conditions affecting the skeletal system, clinicopathologic meetings where clinical, radiological, and pathological assessments made together, are one of the most important steps towards a correct diagnosis.

\section{Conflict of interest}

The authors disclosed no conflict of interest during the preparation or publication of this manuscript.

\section{Financing}

The authors disclosed that they did not receive any grant during conduction or writing of this study.

\section{REFERENCES}

[1] Rosenberg AE, Nielsen GP, Fletcher JA, Kalil RK, Araujo. Aneurysmal bone cyst, Simple bone cyst. In: Fletcher CDM, Unni KK, Mertens F, eds. World Health Organization Classification of Tumours. Pathology and Genetics of Tumours of Soft Tissue and Bone. Lyon: IARC Press, 2002.

[2] Doğanavşargil B, Ayhan E, Argin M, Pehlivanoğlu B, Keçeci B, Sezak M, et al. Cystic bone lesions: histopathological spectrum and diagnostic challenges. Turk Patoloji Derg 2015;31:95-103.

[3] Unni KK, Inwards CY. Miscellaneous unusual tumors of bone. In: Dahlin's Bone Tumors. 6th ed. Philadelphia: Lippincott Williams \& Wilkins, 2010

[4] Oliveira AM, Perez-Atayde AR, Inwards CY, Medeiros F, Derr V, Hsi BL, et al. USP6 and CDH11 oncogenes identify the neoplastic cell 
in primary aneurysmal bone cysts and are absent in so-called secondary aneurysmal bone cysts. Am J Pathol 2004;165:1773-80.

[5] Remotti F, Feldman F. Nonneoplastic lesions that simulate primary tumors of bone. Arch Pathol Lab Med 2012;136:772-88.

[6] Szuhai K, Cleton-Jansen A, Hogendoom PCW, Bovée JVMG. Molecular pathology and its diagnostic use in bone tumors. Cancer Genet 2012;205:193-204.

[7] Unni KK, Inwards CY, Bridge JA, Kindblom L, Wold LE. In: Tumors of The Bones and Joints. AFIP Atlas of Tumor Pathology. Washington, D.C.: American Registry of Pathology, Armed Forces Institute of Pathology, 2005.

[8] Mirra JM, Picci P, Gold RH. In: Bone tumors: clinical, radiologic, and pathologic correlation. Philadelphia: Lea \& Febiger, 1989.

[9] Rapp TB, Ward JP, Alaia MJ. Aneurysmal bone cyst. J Am Acad Orthop Surg 2012;20:233-41.

[10] Martinez V, Sissons HA. Aneurysmal bone cyst. A review of 123 cases including primary lesions and those secondary to other bone pathology. Cancer 1988;61:2291-304.

[11] Lee JW, Kim JH, Han SH, Kang HI. Fibrous dysplasia with aneurysmal bone cyst presenting as painful solitary skull lesion. J Korean Neurosurg Soc 2010;48:551-4.

[12] Yazici B, Yazici Z, Yalcinkaya U. Aneurysmal bone cyst secondary to ossifying fibroma in the orbit. Ophthal Plast Reconstr Surg 2011;27:84-5

[13] Ozan F, Toker G. Secondary aneurysmal bone cyst of the patella. Acta Orthop Traumatol Turc 2010;44:246-9.

[14] Guedes A, Barreto B, Soares Barreto LG, Athanazio DA, Athanazio PR. Calcaneal chondroblastoma with secondary aneurysmal bone cyst: a case report. J Foot Ankle Surg 2010;49:298.e5-8.

[15] Sanerkin NG, Mott MG, Roylance J. An unusual intraosseous lesion with fibroblastic, osteoclastic, osteoblastic, aneurysmal and fibromyxoid elements. "Solid" variant of aneurysmal bone cyst. Cancer 1983;51:2278-86.

[16] Karampalis C, Lenthall R, Boszczyk B. Solid variant of aneurysmal bone cyst on the cervical spine of a child: case report, differential diagnosis and treatment rationale. Eur Spine J 2013;22:523-31.

[17] Gothner M, Citak M, Schildhauer TA, Roetman B. Aneurysmal bone cyst of the spine in an adolescent: a case report. Acta Orthop Belg 2011;77:853-7.

[18] Lee HM, Cho KS, Choi KU, Roh HJ. Aggressive aneurysmal bone cyst of the maxilla confused with telangiectatic osteosarcoma. Auris Nasus Larynx 2012;39:337-40.

[19] Sangle NA, Layfield LJ. Telangiectatic osteosarcoma. Arch Pathol Lab Med 2012;136:572-6.

[20] Mei J, Gao YS, Wang SQ, Cai XS. Malignant transformation of aneurysmal bone cysts: a case report. Chin Med J (Engl) 2009;122:1102.

[21] Brindley GW, Greene JF Jr, Frankel LS. Case reports: malignant transformation of aneurysmal bone cysts. Clin Orthop Relat Res 2005;438:282-7.

[22] Cottalorda J, Bourelle S. Modern concepts of primary aneurysmal bone cyst. Arch Orthop Trauma Surg 2007;127:105-14.

[23] Weinman J, Servaes S, Anupindi SA. Treated unicameral bone cysts. Clin Radiol 2013;68:636-42.

[24] Baumhoer D, Smida J, Nathrath M, Jundt G. The nature of the characteristic cementum-like matrix deposits in the walls of simple bone cysts. Histopathology 2011;59:390-6.

[25] Schajowicz F, Clavel Sainz M, Slullitel JA. Juxta-articular bone cysts (intra-osseous ganglia): a clinicopathological study of eighty-eight cases. J Bone Joint Surg Br 1979;61:107-16.

[26] Kural C, Sungur I, Cetinus E. Bilateral lunate intraosseous ganglia. Orthopedics 2010;33:514.

[27] Lin JD, Koehler SM, Garcia RA, Qureshi SA, Hecht AC. Intraosseous ganglion cyst within the L4 lamina causing spinal stenosis. Spine J 2012;12:9-12.

[28] Bauer TW, Dorfman HD. Intraosseous ganglion: a clinicopathologic study of 11 cases. Am J Surg Pathol 1982;6:207-13.

[29] Gould CF, Ly JQ, Lattin GE Jr, Beall DP, Sutcliffe JB 3rd. Bone tumor mimics: avoiding misdiagnosis. Curr Probl Diagn Radiol 2007;36:124-41.

[30] Simon K, Leithner A, Bodo K, Windhager R. Intraosseous epidermoid cysts of the hand skeleton: a series of eight patients. J Hand Surg Eur 2011;36:376-8.

[31] Kalfas F, Ramanathan D, Mai J, Schwartz S, Sekhar LN. Petrous bone epidermoid cyst caused by penetrating injury to the external ear: case report and review of literature. Asian J Neurosurg 2012;7:93-7.

[32] Nakajo M, Ohkubo K, Nandate T, Nagano Y, Shirahama H, Nakajo M. Intraosseous epidermal cyst of the distal phalanx of the thumb: radiographic and magnetic resonance imaging findings. Radiat Med 2005;23:128-32.

[33] Kural C, Ugras AA, Sungur I, Ozturk H, Erturk AH, Unsaldi T. Hydatid bone disease of the femur. Orthopedics 2008;31:712.

[34] Guney M, Tekeli H, Kendirli MT, Kaya S, Turhan V, Sonmez G, et al. Intramedullary hydatid cyst of the cervical spine. Indian J Med Microbiol 2012;30:480-1.

[35] Ahmad M, Ekramullah, Ahmad I, Ali SA. A rare case of intradural spinal hydatid cyst in a paediatric patient. JBR-BTR 2012;95:87-8.

[36] Kapoor SK, Kataria H, Patra SR, Bharadwaj M, Vijay V, Kapoor $\mathrm{S}$. Multi-organ hydatidosis with extensive involvement of the hemipelvis and ipsilateral femur. Parasitol Int 2013;62:82-5. 